\title{
Caries Distribution, Prevalence, and Treatment Needs among 12-15-Year-Old Secondary School Students in Port Harcourt, Rivers State, Nigeria
}

\author{
Omoigberai Bashiru Braimoh, ${ }^{1}$ Ayamma Udo Umanah, ${ }^{2}$ and Nzube Anthony Ilochonwu ${ }^{1}$ \\ ${ }^{1}$ Department of Preventive Dentistry, Faculty of Dentistry, College of Health Sciences, University of Port Harcourt, Choba, \\ Port Harcourt, Rivers State 500001, Nigeria \\ ${ }^{2}$ Department of Restorative Dentistry, Faculty of Dentistry, College of Health Sciences, University of Port Harcourt, Choba, \\ Port Harcourt, Rivers State 500001, Nigeria
}

Correspondence should be addressed to Omoigberai Bashiru Braimoh; doc_obm@yahoo.com

Received 23 August 2014; Revised 2 November 2014; Accepted 4 November 2014; Published 20 November 2014

Academic Editor: Wael Al-Omari

Copyright (C) 2014 Omoigberai Bashiru Braimoh et al. This is an open access article distributed under the Creative Commons Attribution License, which permits unrestricted use, distribution, and reproduction in any medium, provided the original work is properly cited.

Objective. There is a change in the trends and distribution of dental caries in established and nonestablished market economies. The aim of this study was to describe caries distribution, prevalence, and treatment needs among school children in Port Harcourt, Nigeria. Materials and Methods. The study was a cross-sectional survey of students between the ages of 12 and 15 years. Data was collected using a structured questionnaire and clinical oral examination. Analysis of data was done using statistical package for social science version 20.0. Association between variables was tested using chi-square, independent $t$-test, and one-way analysis of variance. Results. The study population consisted of 195 school children of mean age $13.21 \pm 1.09$ years. The prevalence of dental caries was $15.4 \%(n=30)$. The mean DMFT score for the entire group was $0.25 \pm 0.66$. Dental caries occurred more significantly $(P<0.005)$ on the mandible $(66.7 \%)$ than on the maxilla $(33.3 \%)$ and was significantly $(P<0.005)$ more prevalent on the first molars (66.7\%) than on the second molars (26.6\%). Conclusion. The number of untreated dental caries was high and the restorative index was low among the students. The overall caries prevalence and mean DMFT were low even when compared to other studies in similar populations in Nigeria.

\section{Introduction}

World Dental Federation (FDI) and World Health organization (WHO) in 1982 developed the global goal for oral health by the year 2000 as a strategy for the promotion of oral health globally [1]. This became necessary because of the global burden of oral diseases. This includes dental caries, periodontal diseases, edentulism, oral mucosa lesions, oral lesions in human immunodeficiency virus/AIDS (HIV/AIDS), and orodental trauma $[2,3]$. The objectives of this global goal were to reduce the prevalence of dental caries such that $50 \%$ of 5-6 year olds would be caries free, the global mean DMFT should not be more than 3 at the age of 12 , and $85 \%$ of the population should have all their teeth in the mouth at the age of 18 . Other objectives include $50 \%$ and $25 \%$ reduction in edentulousness, respectively, among 35-44-year olds and 65 -year olds and above age groups [1]. A review of these goals in 2000 revealed that while these goals were achieved or even exceeded in some countries, it was an unrealizable dream for most countries [4].

Dental caries and periodontal diseases contribute to the global burden of oral diseases and still constitute major public health concern in spite of improvement in oral health globally $[2,3]$. In Africa, including Nigeria, caries prevalence and mean DMFT (decayed, missing, and filled teeth) are low as compared to industrialized countries. The mean DMFT among 12-year-old school children in Africa is between 0.5 and $2.6[2,3]$. A number of epidemiological surveys reported reduction in the mean DMFT towards the global goal of 3 at the age of 12 in some industrialized countries of the world. 
The decline was attributed to improved self-care practices, effective use of fluoride, and change in living conditions and lifestyle [2, 3, 5-7]. The situation was however different in developing countries, where an increase towards the global goal of 3 was observed, due to limited access to oral health services, lack or inadequate exposure to fluorides, and increased consumption of refined sugars $[2,3,8]$.

In Nigeria, caries prevalence varies between $4 \%$ and $40 \%$ and mean DMFT/dmft varies between 0.5 and 3.5 [8-16]. It is reported to be higher in urban than in rural population and private than in public schools and increases with age [8-15]. There is a paucity of data on caries experience in the Niger Delta region of Nigeria. The only available data is on caries experience among adults attending dental hospital [16]. This study reported a mean DMFT of 3.5; this is higher than those reported among school children in Nigeria [1015]. The aim of the present study was to describe caries distribution, prevalence, and treatment needs among secondary school children in Port Harcourt, Rivers State Nigeria. The study would provide baseline information on the extent and severity of dental caries in the population, in addition to patterns of its occurrence in relation to gender, socioeconomic status, and age.

\section{Materials and Methods}

The study was a cross-sectional survey of students between the ages of 12 and 15 years from a secondary school located at Choba in Port Harcourt, Rivers State. The school was randomly selected among three other secondary schools in the area by balloting. All the students within the age 12-15 years irrespective of the level of study were selected. During the survey, health education campaign against cigarette smoking, alcohol consumption, and the prevention and control of dental caries was given to the students. Ethical approval was obtained from the Research and Ethics Committee of the University of Port Harcourt Teaching Hospital and consent to take part in the study was obtained from parents through the school authority. The calibration of the two examiners was done on three different occasion using 10 patients. The measurements obtained were subjected to Cohen's Kappa statistics and intraclass correlation coefficient for intraexaminer and interexaminer reliability giving values of 0.9 and 0.8 , respectively.

Data was collected over a period of two weeks using a structured questionnaire made up of two sections. Section 1 which was interviewer-administered had information on age, gender, and occupation of parents. Based on the occupation of parents, the students were grouped into different social classes using the classification modified by Arowojolu (2001) [17].

Social Class I-Executive managers, company directors, professionals (doctors, lawyers, engineers), university professors, traditional chiefs; Social class II-Civil servants, nurses, professional teacher, secretaries, clergymen, businessman and pensioners; Social class III (Semi-skilled)Tailors, bricklayers, carpenters, typists, sewing mistresses, clerk, house wife; Social class IV (Unskilled)-Messengers, roadside traders, cleaners, night-guards, farmers.
TABLE 1: Mean DMFT scores according to gender, age, and socioeconomic class of the students.

\begin{tabular}{lccc}
\hline Variable & Frequency Percentage & $\begin{array}{c}\text { Mean DMFT } \\
\pm \text { SD }\end{array}$ \\
\hline Age in years & & & \\
12 & 66 & 33.9 & $0.21 \pm 0.60$ \\
13 & 56 & 28.7 & $0.23 \pm 0.64$ \\
14 & 39 & 20.0 & $0.27 \pm 0.61$ \\
15 & 34 & 17.4 & $0.29 \pm 0.80$ \\
Total & $\mathbf{1 9 5}$ & $\mathbf{1 0 0}$ & $\mathbf{0 . 2 5} \pm \mathbf{0 . 6 6}$ \\
Sex & & & \\
Male & 89 & 45.6 & $0.22 \pm 0.60$ \\
Female & 106 & 54.4 & $0.26 \pm 0.71$ \\
Total & $\mathbf{1 9 5}$ & $\mathbf{1 0 0}$ & $\mathbf{0 . 2 5} \pm \mathbf{0 . 6 6}$ \\
Parent socioeconomic status & & & \\
Class I & 31 & 15.9 & $0.29 \pm 0.74$ \\
Class II & 95 & 48.7 & $0.24 \pm 0.65$ \\
Class III & 10 & 5.1 & $0.16 \pm 0.45$ \\
Class IV & 59 & 30.3 & $0.10 \pm 0.32$ \\
Total & $\mathbf{1 9 5}$ & $\mathbf{1 0 0}$ & $\mathbf{0 . 2 5} \pm \mathbf{0 . 6 6}$ \\
\hline
\end{tabular}

Section 2 recorded dental caries during clinical oral examination. Oral examination was done under natural light using examination gloves and wooden spatula with patient seated on a plastic chair with a high backrest and examiner standing in front of the chair. DMFT was recorded and calculated using WHO guideline of Oral Health Surveys Basic Methods 2013 [18]. Restorative index, a measure of restorative care of those who had experienced dental caries, was also calculated. It represents the number of filled teeth divided by the sum of filled and decayed teeth expressed in percentage [19]. Data on decayed, missing, and filled primary teeth were excluded from the analysis.

Collected data were entered into Statistical Package for Social Science (IBM Statistics New York, USA) spreadsheet and analyzed using Version 20.0. Descriptive summary statistics was obtained for demographic variables and difference in proportion was tested using Chi-square tests at 95\% confidence interval. $P<0.05$ was considered to be statistically significant. Difference in mean was also tested using independent sample $t$-test for two groups and one-way analysis of variance (ANOVA) for more than two groups.

\section{Results}

The mean age of the participants was $13.21 \pm 1.09$ years with a median of 13.0 years. The age distribution of the respondents showed that $66(33.8 \%)$ were 12 years, $56(28.7 \%)$ were 13 years, 39 (20.0\%) were 14 years, and 34 (17.4\%) were 15 years. There were $89(45.6 \%)$ boys with a mean age of $13.17 \pm 1.12$ years and 106 (54.4\%) girls with a mean age of $13.25 \pm$ 1.08 years. There was no significant difference in the mean ages between the groups. Regarding socioeconomic status, 31 (15.9\%) of the respondents belonged to the class I, 95 (48.7\%) belonged to class II, 10 (5.1\%) belonged to class III, and 59 (30.3\%) belonged to class IV (Table 1 ). 
TABLE 2: Number and percentage distribution of dental caries according to sex among the students.

\begin{tabular}{lccc}
\hline Variable & Male & Female & Total \\
\hline Dental caries & & & \\
Present & $14(7.2)$ & $16(8.2)$ & $30(15.4)$ \\
Absent & $75(38.5)$ & $90(46.2)$ & $165(84.6)$ \\
Total & $\mathbf{8 9 ( 4 5 . 6 )}$ & $\mathbf{1 0 6 ( 5 4 . 4 )}$ & $\mathbf{1 9 5 ( 1 0 0 )}$ \\
\hline
\end{tabular}

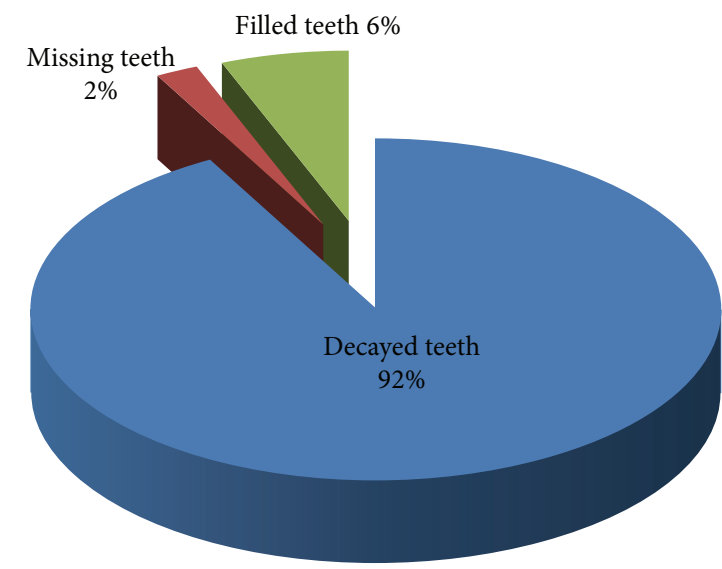

FIGURE 1: Contribution of decayed, missing, and filled components to DMFT.

The majority of students were caries free $N=165(84.6 \%)$ giving a dental caries prevalence of $15.4 \%$ (Table 2). The mean DMFT score for the whole group was $0.25 \pm 0.66$. The prevalence and mean DMFT were higher in girls $0.26(8.2 \%)$ than boys $0.22(7.2 \%)$ (Tables 1 and 2). The mean DMFT scores at the ages of $12,13,14$, and 15 were $0.21,0.23,0.27$, and 0.29 , respectively. According to the socioeconomic status of the parents, the mean DMFT scores in descending order of magnitude were class I, 0.29 ; class II, 0.24 ; class III, 0.16; and class IV, 0.10 (Table 1). There was no significant difference $(P>0.05)$ in mean DMFT in relation to gender, age, and parent's socioeconomic status. Decayed teeth (DT) were a major contributor to the DMFT; the proportion of decayed, missing, and filled teeth was 92\%, 2\%, and 6\%, respectively (Figure 1). Females had more decayed, missing, and filled teeth than the males. Among the individuals who had a DMFT $\geq 1$, caries accounted for the $92 \%$ and, of these, $67 \%$ had only one carious lesion DT = 1 (see Figure 2).

Significantly more carious teeth were recorded on the mandible $(66.7 \%)$ than the maxilla $(P<0.005)$ and were significantly more prevalent on the first molars $(66.7 \%)$ than the second molars $(P<0.005)$. The premolar and central and lateral incisors had one carious lesion each and no caries was seen in the canine (Table 3).

\section{Discussion}

Several hours are reportedly lost each year all over the world at home, at work, and in schools due to the impact of oral diseases. Oral diseases vary in distribution and severity within the same country or region and different parts of the world.

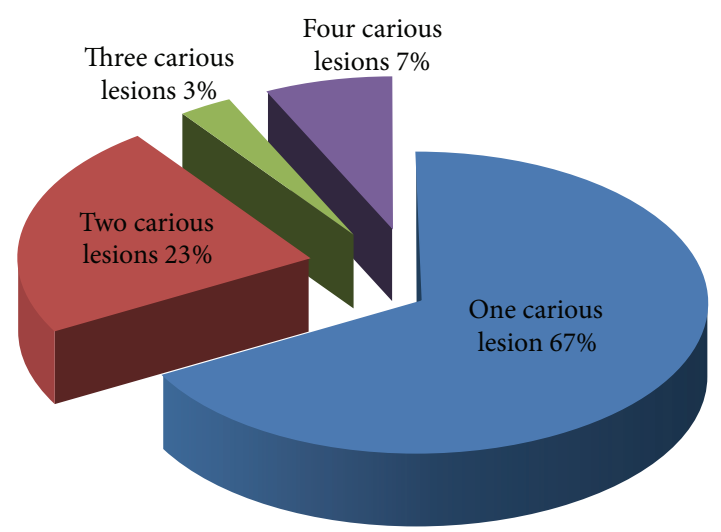

FIGURE 2: Distribution of the number of carious lesions among the students.

TABLE 3: Distribution of caries between the jaws and among different teeth in the participants.

\begin{tabular}{lcc}
\hline Variable & Number & Percentage \\
\hline Tooth type & 30 & $66.7^{*}$ \\
$\quad$ First molars & 12 & 26.6 \\
Second molars & 3 & 6.7 \\
$\quad$ Other teeth ${ }^{\varphi}$ & 15 & 33.3 \\
Jaw & 30 & $66.7^{*}$ \\
$\quad$ Maxilla & & \\
$\quad$ Mandible &
\end{tabular}

A number of epidemiological studies have shown the role of sociobehavioral and environmental factors in oral diseases $[2,3]$. These surveys are necessary for the development of oral health policies and implementation of effective oral health care program at community level.

This survey presents the caries experience among secondary school children in Port Harcourt, Rivers State, Nigeria. Caries prevalence in this study was $15.4 \%$, which is less than $22.6 \%$ reported among adult attendees at the University of Port Teaching Hospital [16]. The variation may be due to the difference in the study population and dental visits motivated by pain. Furthermore, when compared to similar studies carried out among secondary school children in other parts of the country (Benin, 33\%; Enugu, 24.1\%), the reported prevalence in this study was low $[10,13]$. This may be explained by the difference in socioeconomic background, oral hygiene practices, and intake of refined sugar.

Dental caries was significantly more prevalent in the first molars compared to the second molars. The result of this study may be in line with the changing trend in caries being observed in developing countries due to increased consumption of refined sugar $[2,3]$. The early exposure of first molars to cariogenic diet as they erupt into the mouth could also play a role. Exposure to highly cariogenic diet promotes the colonization of pits and fissures of the first molars, making them more susceptible to caries [8]. This observation was different from other studies which reported that second 
molars were frequently more involved in the decay process than the first molars $[19,20]$. In addition, mandibular teeth were significantly more often found to be decayed than maxillary teeth. Higher prevalence of caries in the mandible in the present study may be related to greater food packing and plaque accumulation potential in the mandible than in the maxilla and faster caries progression in the mandibular molar teeth [21].

The mean DMFT score was higher in girls than boys, though not significant. Other studies have reported higher mean score in girls than boys with no significant difference $[10,22]$. However, while Udoye et al. [13] reported a significantly higher mean DMFT score in girls as compared to boys, Pakpour et al. [23] reported significantly higher mean DMFT score in boys than girls. The higher prevalence of dental caries and mean DMFT score seen among females in this study might be attributed to early exposure of the teeth to the oral environment in females [24]. In the present study, there was an increase in DMFT score with age; this is similar to the reported increase seen in other studies [10, 13, 23, 25].

Mean DMFT is higher in private school children when compared to those in public schools and in urban than in rural schools. Private schools are expensive, effectively administered, and better equipped than public schools financed by the government. These schools are located in urban centers and are owned and run by individual proprietors and nongovernmental organizations [10]. Attending a private school and living in an urban area is a function of socioeconomic status. The results of this study showed that social disparity is a factor in DMFT score. School children whose parents belonged to higher social class (classes I and II) had higher DMFT score as compared to children of lower social class (classes III and IV) parents. Pakpour et al. [23] and Jürgensen and Petersen [26] reported similar findings. The greater incidence of caries seen in this group may be due to the ability of their parents to buy more snacks, sweets and other refined sugar products than children whose parents belonged to lower social class. Furthermore, it may also be due greater oral health awareness among parents of students belonging to higher socioeconomic class.

High DMFT score is not a common feature in Nigeria; the severity of dental caries based on mean DMFT varies from very low to low $[2,4,8]$. The major concern, however, is the reported increase in mean DMFT score $[2,4,8]$. This study did not show an increase in mean DMFT when compared to other studies which reported mean DMFT ranging from 0.5 to 3.5 [8-16]. The overall mean and mean at 12 years were considerably less than the global mean of three proposed by WHO and FDI for the year 2000 for all countries of the world. This finding was in agreement with the study of Akpata [8], who reported that the increase in mean DMFT score among school children in Nigeria was probably apparent rather than real, due to different methodologies and caries diagnostic criteria used in these studies. However, effort should be made to further reduce the mean DMFT or at least maintain this low score reported among the Nigerian populace. This could be achieved through emphasis on prevention, including improved oral health awareness, self-care practices, effective use of fluoride, utilization of dental services, and maintaining healthy environment and lifestyle. Furthermore, there is a need to develop and use indices that would allow prompt and early diagnosis of dental caries in epidemiological survey at the incipient stage rather than at the level of established cavity.

The number of carious lesions observed in each subject varied from at least one to four. The majority (67\%) of the subjects had one carious lesion. In a similar study among secondary school children between the ages of 12 and 15 years [10] and another [27] among prison inmates, the majority of the respondents had at least one carious lesion.

Epidemiological studies have reported the D part of the DMF index to be responsible for most of all the caries observed in the study populations. In Enugu [13] and Benin [10], the D component accounted for $91.3 \%$ and $98.6 \%$, respectively, of the entire DMFT. This is in line with the result obtained in the present survey where $\mathrm{D}$ component accounted for $92 \%$ of the DMFT. The high percentage of untreated teeth is consistent with findings from other underdeveloped and developing countries [28, 29]. A high number of untreated dental caries among school children have been attributed to limited access to dental care [30, 31].

Restorative index is a measure of those with dental caries who had received previous restorative dental care. Only $6.3 \%$ of the students in the current study had received restorative treatment, indicating a high need for restorative care among the students. The result of this study is comparable to $3.5 \%$ reported in Ibadan [14] among 14-year-old school children but lower than 25.3\% [16] documented among hospital patients in Port Harcourt. Therefore, in the present study, the distribution of dental caries was not modified by provision of dental care; this makes the students suitable for the study of caries patterns.

Dental caries was diagnosed based on WHO diagnostic criteria [18]; therefore, incipient carious lesions were not recorded as decayed teeth. These lesions have the ability to remineralize without progressing to overt caries. Similarly, interproximal caries is best detected by the use of radiograph; only interproximal caries with overt cavitations were recorded as decayed teeth. These could lead to underestimation of the actual prevalence dental caries and DMFT value. In spite of this limitation, DMFT index is simple, easy, and fast to use; it is universally acceptable and applicable and has been in use for decades.

\section{Conclusion}

The number of untreated dental caries was high and the restorative index was low among the students. The overall caries prevalence and mean DMFT were low even when compared to other studies in similar populations in Nigeria. Efforts should, therefore, be made to further reduce the mean DMFT or at least sustain this low prevalence through an effective prevention program.

\section{Conflict of Interests}

No support in the form of grant was received for this study and no conflict of interests exists between the authors. 


\section{Authors' Contribution}

The authors Drs. Omoigberai Bashiru Braimoh, Ayamma Udo Umanah, and Nzube Anthony Ilochonwu were involved in the concept and design of this study, collection, analysis, and interpretation of data, and the final drafting, revising, and approval of the paper for submission to this journal. They take responsibility for the integrity of this work as a whole from inception to publication and give the rights to the corresponding author, Dr. Omoigberai Bashiru Braimoh to make necessary changes as per the request of the journal, do the rest of the correspondence on their behalf, and act as the guarantor for the paper.

\section{Acknowledgment}

The authors wish to express their gratitude to the principal, staff, and students of the school visited.

\section{References}

[1] Federation Dentaire Internationale/World Health Organization, "Global goals for oral health in the year 2000," International Dental Journal, vol. 23, pp. 74-77, 1982.

[2] P. E. Petersen, D. Bourgeois, H. Ogawa, S. Estupinan-Day, and C. Ndiaye, "The global burden of oral diseases and risks to oral health," Bulletin of the World Health Organization, vol. 83, no. 9, pp. 661-669, 2005.

[3] World Health Organization, The World Oral Health Report, 2003, World Health Organization, Geneva, Switzerland, 2003.

[4] M. Hobdell, P. E. Petersen, J. Clarkson, and N. Johnson, "Global goals for oral health 2020," International Dental Journal, vol. 53, no. 5, pp. 285-288, 2003.

[5] L. J. Brown, T. P. Wall, and V. Lazar, "Trends in caries among adults 18 to 45 years old," The Journal of the American Dental Association, vol. 133, no. 7, pp. 827-834, 2002.

[6] M. C. Downer, "Caries prevalence in the United Kingdom," International Dental Journal, vol. 44, supplement 1, pp. 365-370, 1994.

[7] F. R. von der Fehr, "Caries prevalence in the Nordic countries," International Dental Journal, vol. 44, no. 4, pp. 371-378, 1994.

[8] E. S. Akpata, "Oral health in Nigeria," International Dental Journal, vol. 54, no. 6, pp. 361-366, 2004.

[9] A. O. Adegbembo, M. A. El-Nadeef, and A. Adeyinka, "National survey of dental caries status and treatment needs in Nigeria," International Dental Journal, vol. 45, no. 1, pp. 35-44, 1995.

[10] S. A. Okeigbemen, "Prevalence of dental caries among 12-15year-old school children in Nigeria: report of a local survey and campaign," Oral Health \& Preventive Dentistry, vol. 2, pp. 29-31, 2004.

[11] O. O. Sofola, S. O. Jeboda, and O. P. Shaba, "Dental caries status of primary school children aged 4-16 years in southwest Nigeria," Odonto-Stomatologie Tropicale: Tropical Dental Journal, vol. 27, no. 108, pp. 19-22, 2004.

[12] M. O. Noah, “The prevalence and distribution of dental caries and gingivitis in 6-year-old children attending free-government schools in Ibadan, Nigeria," Odonto-stomatologie Tropicale, vol. 7, no. 3, pp. 119-127, 1984.
[13] C. I. Udoye, E. N. Aguwa, R. U. Chikezie, M. O. Ezekenwa, O. Jerry-Oji, and C. I. Okpaji, "Prevalence and distribution of caries in 12-15 year urban school children in Enugu," The Internet Journal of Dental Science, vol. 7, no. 2, 2009.

[14] O. Denloye, D. Ajayi, and O. Bankole, "A study of dental caries prevalence in 12-14 years old school children in Ibadan, Nigeria," Journal of Paediatric Dentistry, vol. 15, pp. 147-151, 2005.

[15] C. A. Adekoya-Sofowora, W. O. Nasir, A. O. Oginni, and M. Taiwo, "Dental caries in 12-year-old suburban Nigerian school children," African Health Sciences, vol. 6, no. 3, pp. 145-150, 2006.

[16] O. G. Omitola and A. O. Arigbede, "Prevalence of dental caries among adult patients attending a tertiary dental institution in South-South region of Nigeria," Port Harcourt Medical Journal, vol. 6 , no. 1, pp. 52-58, 2011.

[17] M. O. Arowojolu, "Effect of social class on the prevalence and severity of periodontal diseases," The Nigerian Medical Practitioner, vol. 39, pp. 26-28, 2001.

[18] World Health Organization, Oral Health Surveys-Basic Methods, World Health Organization, Geneva, Switzerland, 5th edition, 2013.

[19] E. S. Akpata and D. Jackson, "Caries vulnerability of first and second permanent molars in urban Nigerians," Archives of Oral Biology, vol. 23, no. 9, pp. 795-800, 1978.

[20] K. Westwater, "A study of the relative caries prevalence in first and second permanent molars of rural Zambian schoolchildren," Journal of Dentistry, vol. 5, no. 1, pp. 42-46, 1977.

[21] I. Kleinberg and G. N. Jenkins, “The $\mathrm{pH}$ of dental plaques in the different areas of the mouth before and after meals and their relationship to the $\mathrm{pH}$ and rate of flow of resting saliva," Archives of Oral Biology, vol. 9, no. 5, pp. 493-516, 1964.

[22] A. R. Daneshkazemi and A. Davari, "Assessment of DMFT and enamel hypoplasia among junior high school children in Iran," Journal of Contemporary Dental Practice, vol. 6, no. 4, pp. 85-92, 2005.

[23] A. H. Pakpour, A. Hidarnia, E. Hajizadeh, S. Kumar, and A.-P. Harrison, "The status of dental caries and related factors in a sample of Iranian adolescents," Medicina Oral, Patologia Oral y Cirugia Bucal, vol. 16, no. 6, pp. e822-e827, 2011.

[24] S. Kaul, S. Saini, and B. Saxena, "Emergence of permanent teeth in school children in Chandigarh, India," Archives of Oral Biology, vol. 20, no. 9, pp. 587-593, 1975.

[25] K. F. Woodmansay, "The prevalence of dental caries among international students at U.S. universities," Journal of Contemporary Dental Practice, vol. 6, pp. 124-135, 2005.

[26] N. Jürgensen and P. E. Petersen, "Oral health and the impact of socio-behavioural factors in a cross sectional survey of 12 year old school children in Laos," BMC Oral Health, vol. 9, no. 1, article 29, 2009.

[27] O. B. Braimoh, O. O. Sofola, and S. A. Okeigbemen, "Caries and periodontal health status of prison inmates in Benin City, Nigeria," International Journal of Biomedical and Health Sciences, vol. 7, pp. 137-145, 2011.

[28] E. C. Lo, C. J. Holmgren, D.-Y. Hu, and H.-C. Wan, "Dental caries status and treatment needs of 12-13 year-old children in Sichuan Province, Southwestern China," Community Dental Health, vol. 16, no. 2, pp. 114-116, 1999. 
[29] I. Okullo, A. N. Åstrøm, O. Haugejorden, and C. M. Rwenyonyi, "Variation in caries experience and sugar intake among secondary school students in urban and rural Uganda," Acta Odontologica Scandinavica, vol. 61, no. 4, pp. 197-202, 2003.

[30] A. Singh, M. P. Bharathi, P. Sequeira, S. Acharya, and M. Bhat, "Oral health status and practices of 5 and 12 year old indian tribal children," Journal of Clinical Pediatric Dentistry, vol. 35, no. 3, pp. 325-330, 2011.

[31] B. Peng, P. E. Petersen, M. W. Fan, and B. J. Tai, "Oral health status and oral health behaviour of 12-year-old urban schoolchildren in the People's Republic of China," Community Dental Health, vol. 14, no. 4, pp. 238-244, 1997. 


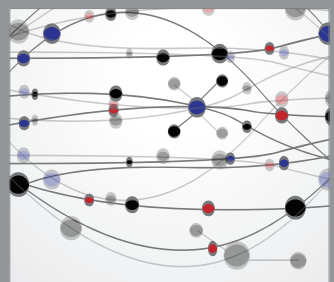

The Scientific World Journal
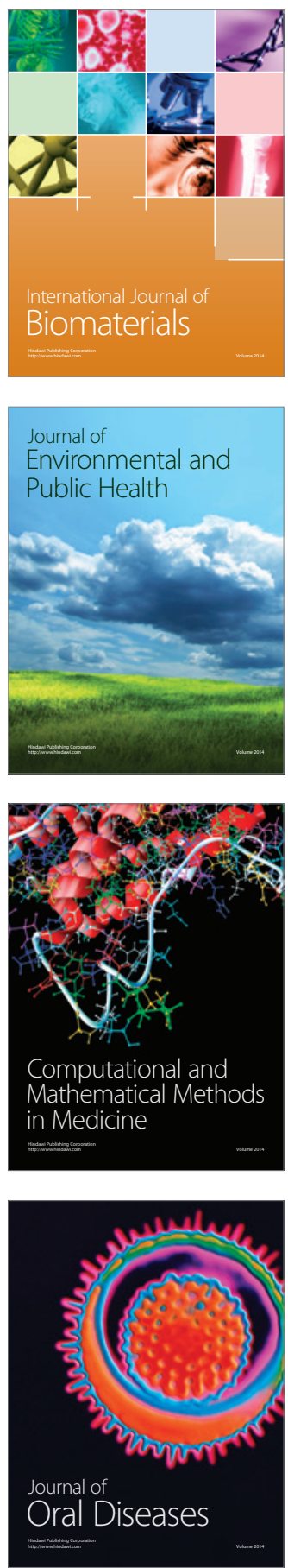
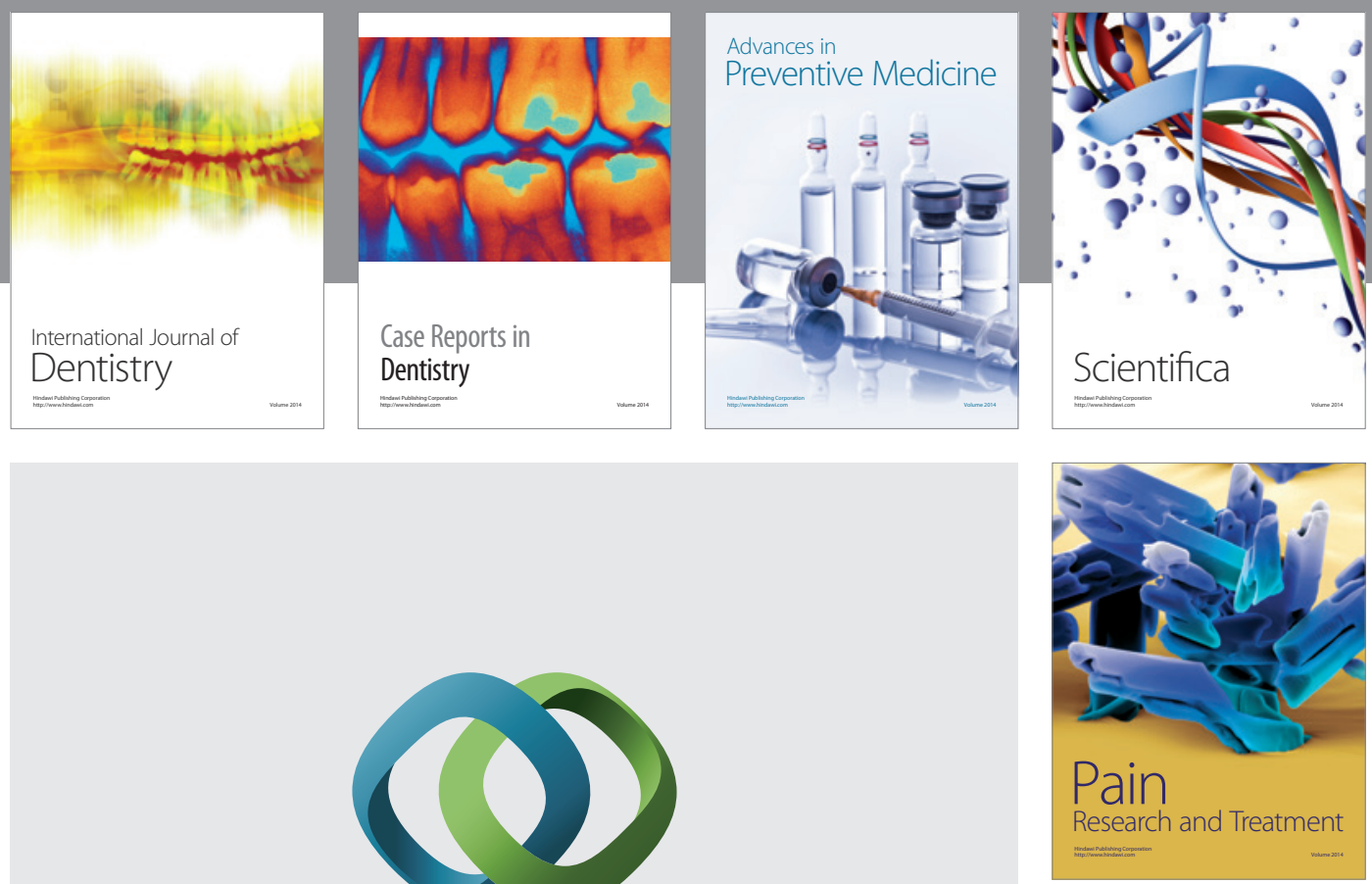

\section{Hindawi}

Submit your manuscripts at

http://www.hindawi.com
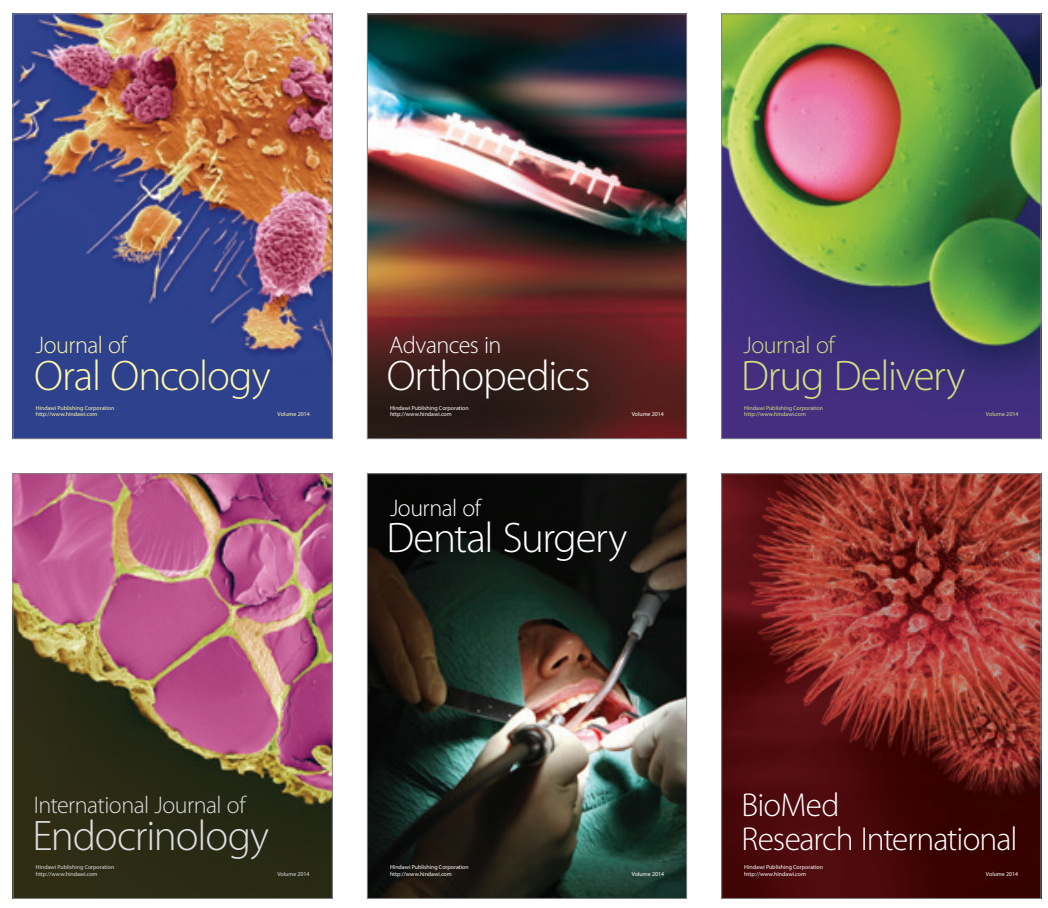

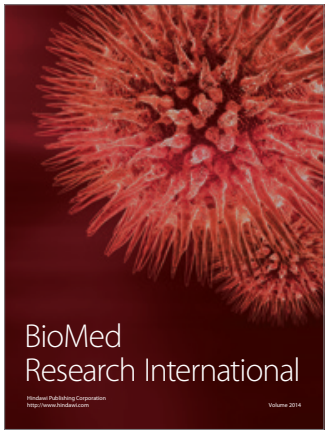

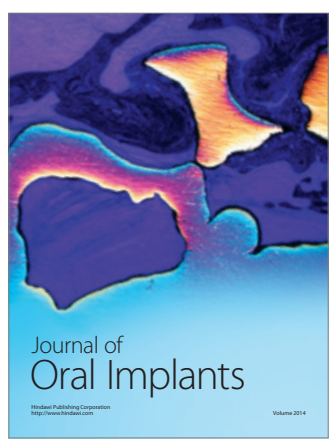
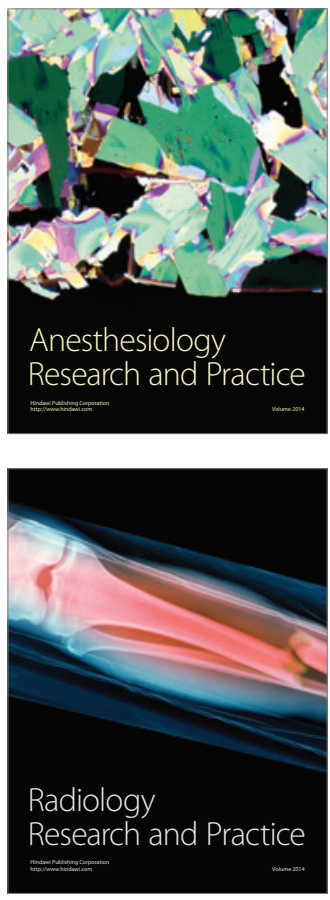